\title{
Patient-related barriers to hypertension control in a Nigerian population
}

This article was published in the following Dove Press journal:

International Journal of General Medicine

3 July 2014

Number of times this article has been viewed

\section{Chimezie Godswill \\ Okwuonu'}

Nnamdi Ezekiel Ojimadu²

Enajite Ibiene Okaka ${ }^{3}$

Fatai Momodu Akemokwe ${ }^{4}$

'Nephrology Unit, Department of Internal Medicine, ${ }^{2}$ Department of Family Medicine, Federal Medical

Center Umuahia, Abia State, ${ }^{3}$ Renal Unit, ${ }^{4}$ Neurology Unit, Department of Internal Medicine University of Benin Teaching Hospital, Benin City, Nigeria

Video abstract

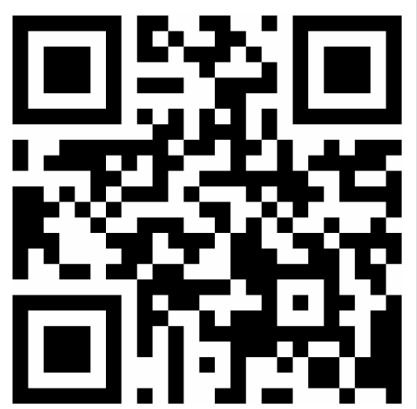

Point your SmartPhone at the code above. If you have a QR code reader the video abstract will appear. Or use: http://dvpr.es/UDONbV
Correspondence: Chimezie Godswill Okwuonu

Nephrology Unit, Department of Internal Medicine, Federal Medical Center PO Box 1229, Umuahia, Abia State, Nigeria

Mob +234803889680I

Email getchimezie@yahoo.com
Background: Hypertension control is a challenge globally. Barriers to optimal control exist at the patient, physician, and health system levels. Patient-related barriers in our environment are not clear. The aim of this study was to identify patient-related barriers to control of hypertension among adults with hypertension in a semiurban community in South-East Nigeria.

Methods: This was a cross-sectional descriptive study of patients with a diagnosis of hypertension and on antihypertensive medication.

Results: A total of 252 participants were included in the survey, and comprised 143 males $(56.7 \%)$ and 109 females $(43.3 \%)$. The mean age of the participants was $56.6 \pm 12.7$ years, with a diagnosis of hypertension for a mean duration of $6.1 \pm 3.3$ years. Among these patients, $32.9 \% \mathrm{had}$ controlled blood pressure, while $39.3 \%$ and $27.8 \%$, respectively, had stage 1 and stage 2 hypertension according to the Seventh Report of the Joint National Committee on Prevention, Detection and Evaluation of High Blood Pressure. Only 23.4\% knew the consequences of poor blood pressure control and $64 \%$ were expecting a cure from treatment even when the cause of hypertension was not known. Furthermore, $68.7 \%$ showed low adherence to medication, the reported reasons for which included forgetfulness (61.2\%), financial constraints (56.6\%), high pill burden (22.5\%), side effects of medication (17.3\%), and low measured blood pressure (12.1\%). Finally, knowledge and practice of the lifestyle modifications necessary for blood pressure control was inadequate among the participants.

Conclusion: Poor knowledge regarding hypertension, unrealistic expectations of treatment, poor adherence with medication, unawareness of lifestyle modification, and failure to apply these were identified as patient-related barriers to blood pressure control in this study.

Keywords: Blood pressure, medication adherence, knowledge of hypertension, proteinuria, diabetes mellitus, lifestyle modification

\section{Introduction}

Hypertension is the leading cause of cardiovascular disease worldwide, ${ }^{1,2}$ and is the major cause of death and second leading cause of disability after childhood malnutrition globally. ${ }^{3}$ Briganti et al reported that almost one third of Australian adults may have hypertension. ${ }^{4}$ In sub-Saharan Africa, hypertension is the most rapidly increasing cardiovascular disease, affecting over 20 million people and being the most common cardiovascular cause of hospitalization and mortality. ${ }^{5}$ Hypertension ranks first among the noncommunicable diseases in Nigeria, ${ }^{6}$ with a prevalence ranging from $8 \%$ to $46.4 \%$ in men and women in rural and urban communities. ${ }^{7-12}$

Although improving the quality of care for hypertension is a priority, most hypertensive patients have inadequately controlled blood pressure, ${ }^{13,14}$ leading to an increased risk of coronary artery disease, congestive heart failure, renal insufficiency, and stroke. ${ }^{13}$ 
In addition, knowledge of hypertension on the part of patients is low, and control of blood pressure is generally suboptimal in rural and urban communities. ${ }^{15-17}$

Hypertension is considered to be controlled when systolic blood pressure is less than $140 \mathrm{mmHg}$ and diastolic blood pressure is less than $90 \mathrm{mmHg} .{ }^{18,19}$ Population surveys have shown that hypertension is either untreated or inadequately controlled in about $70 \%-75 \%$ of people worldwide, despite advances in drug treatment that have made life more tolerable for hypertensives. ${ }^{20}$ Barriers to blood pressure control appear to exist at the patient, physician, and system levels. Patient-related barriers include poor knowledge concerning hypertension and its consequences, ${ }^{21-23}$ the side effects of antihypertensive drugs, ${ }^{23}$ poor adherence with drug therapy (a major factor), ${ }^{24,25}$ erroneous health beliefs, ${ }^{26,27}$ inability to make lifestyle changes, unrealistic expectations of treatment (for example, expecting a cure), ${ }^{28}$ and demographic factors (eg, socioeconomic status, educational level, age, sex). ${ }^{29}$ Poor adherence with therapeutic guidelines, ${ }^{30}$ inadequate understanding of therapeutic goals, ${ }^{21,31}$ and failure to emphasize the lifestyle modifications necessary in the management of hypertension ${ }^{32,33}$ are major physician-related barriers. Further, an inefficient health care system ${ }^{34}$ and low socioeconomic status ${ }^{35}$ may present a barrier to blood pressure control, given that the inaccessibility of hospitals and high costs of screening and treatment may hinder optimal control of hypertension in the low socioeconomic groups. ${ }^{36}$

Currently, safe and effective antihypertensive medications are readily available for most hypertensive patients. ${ }^{15}$ Therefore, it is of paramount importance to identify barriers to obtaining optimal blood pressure control as they relate to patients. This is necessary to maximize the therapeutic effects of these drugs and to reduce the morbidity and mortality associated with hypertension. Most Nigerian studies on blood pressure control and related factors in hospital settings $\mathrm{s}^{37,38}$ and rural/semiurban communities ${ }^{17,39}$ have not focused on patient-related barriers to hypertension control. A few have assessed the knowledge base of patients ${ }^{40}$ and their adherence to medication, ${ }^{40-42}$ but assessed the latter using nonvalidated tools developed by the researchers themselves for their own research purposes.

We therefore set out to identify patient-related barriers to hypertension control in a representative adult population of hypertensives in a semiurban area of South-East Nigeria. The findings of this study will add to the existing body of knowledge and help initiate concerted efforts towards curbing the rising prevalence of uncontrolled hypertension in our region.

\section{Materials and methods}

\section{Study design and site}

This was a descriptive cross-sectional questionnaire-based study carried out in Olokoro, a semiurban community in the Umuahia South local government area of Abia State, South-East Nigeria. The community is about 8 kilometers from Umuahia township, the state capital. The inhabitants are predominantly Christians and most are traders or artisans with a few civil servants and farmers.

\section{Study population}

The study population included all adults with a previous diagnosis of hypertension made by medical personnel and on antihypertensive medication at the time of the study. They were identified during a medical screening exercise carried out in Olokoro, Umuahia South local government area of Abia State, South-East Nigeria, from August 15 to 18, 2013.

\section{Sample size and sampling}

The proportion of patients adhering to their antihypertensive medication in a hospital-based study in Umuahia was $42.9 \%{ }^{42}$ The sample size in this study was extrapolated from this value at a $95 \%$ confidence level with a $5 \%$ margin of error using appropriate formulae. ${ }^{43}$ This gave a minimum sample size of 376 . However, 390 patients were included to allow for attrition.

\section{Inclusion and exclusion criteria}

Consenting adults aged 18 years or older with a previous diagnosis of hypertension made by medical personnel and on antihypertensive medication were included. Patients with a psychiatric illness, an appearance of being chronically ill, or known hypertensive emergency were excluded.

\section{Recruitment and data collection}

The subjects were recruited consecutively. A structured, pretested researcher-administered questionnaire consisting of five sections was used for data collection. The first section canvassed baseline demographic characteristics, including age, sex, educational level, occupation, and duration since diagnosis of hypertension, and social characteristics, ie, alcohol consumption and smoking. The second section was designed to elicit the respondent's knowledge of hypertension and its causes, the consequences of poor blood pressure control, and expectations of treatment. The third section addressed the respondent's knowledge of the lifestyle measures necessary for blood pressure control and their practice of the same. The fourth section assessed adherence to antihypertensive 
medication using a validated eight-item scale designed for use in an outpatient setting. ${ }^{44}$ In a previous study, this scale was reported to have acceptable internal consistency (Cronbach's alpha 0.83 , with items that maintained a high item-to-item correlation ( $>0.4$ for each) and scores that correlated with blood pressure control. ${ }^{44}$ The fifth section documented the participant's blood pressure, weight, height, body mass index, urinalysis, and blood sugar. The face and content validity of the questionnaire was evaluated by a community physician, a cardiologist, and two resident doctors. The questionnaire, written in English, was translated into the local dialect by an expert in that dialect. The translated format was thereafter translated back to English by a second party. The two English versions were then cross-checked for accuracy and consistency in the questions. The interview was conducted in English and the local dialect using interpreters where necessary.

Blood pressure was measured in the nondominant arm using a mercury sphygmomanometer (Accoson, Health Care Equipment, Egham, UK) in the sitting position after resting for 3-5 minutes. Blood pressure was categorized according to the Seventh Report of the Joint National Committee on Prevention, Detection and Evaluation of High Blood Pressure (JNC-VII). ${ }^{19}$ Height was measured using a stadiometer with the participant standing erect, barefoot and without a cap, with the occiput, back, buttock, and heel making contact with a vertical wall. Weight was recorded using a digital bathroom weighing scale.

The subjects were instructed on how to collect a midstream urine specimen. Menstruating females and those with febrile illness or clinical features suggestive of urinary tract infection were excluded from urinalysis. The participants thereafter provided urine samples that were tested using ten parameter urine strips (Chung-Do Pharmaceutical Co, Ltd, Gangwon-Do, Republic of Korea). Individuals with proteinuria of $1+$ or greater were considered to have significant proteinuria. Those with nitrite-positive samples were excluded from subsequent analysis as they were presumed to have urinary tract infection. Blood sugar was analyzed using an Accu-Chek ${ }^{\circledR}$ glucose meter (Roche, Basel, Switzerland). The screening definition for diabetes was based on World Health Organization criteria, ${ }^{45}$ which define random blood sugar of $\geq 11.1 \mathrm{mmol} / \mathrm{L}(200 \mathrm{mg} / \mathrm{dL})$ as diabetes mellitus, or previous diagnosis of diabetes by a physician, or use of hypoglycemic agents.

\section{Data protection}

Data were stored using the Microsoft Excel program, kept secure, and only released for analysis when needed.
Confidentiality was maintained and the anonymity of responses ensured. Personal identifiers were not collected. Permission was obtained from the local government authorities and informed consent from the participants. Anonymity of responses was ensured by nondisclosure of the identity of participants.

\section{Statistical analysis}

The data obtained were analyzed using Statistical Package for the Social Sciences version 21.0 (IBM Corp, Armonk, NY, USA). Continuous variables were expressed as the mean and standard deviation, and categorical variables were expressed as frequencies and proportions. Appropriate diagrams and tables were used to illustrate results where necessary. The chi-square test was used to determine associations between variables. Logistic regression analysis was used to determine the factors associated with the practice of lifestyle modification in those aware of these measures. Statistical significance was assumed at $P<0.05$.

\section{Results}

Complete data was available for 252 participants (a response rate of $64 \%$ ) and used in the analysis. The general characteristics of the patients are shown in Table 1 . The mean age of the patients was $56.6 \pm 12.7$ years, with more males $(n=143,56.7 \%)$ than females $(n=109,43.3 \%)$. The mean duration of diagnosis of hypertension was $6.1 \pm 3.3$ years. At the time of the study, $39.3 \%$ of participants had stage 1 hypertension, $27.8 \%$ had stage 2 hypertension, and $32.9 \%$ had controlled blood pressure according to JNC-VII (Table 1). There was no relationship between the educational attainment of respondents and their blood pressure control ( $\chi^{2}$ with trend $0.53, P=0.47$ ).

Significant proteinuria was found in $12.3 \%$ of the respondents, and diabetes mellitus was found in 5.2\%. Blood pressure control among respondents was not significantly associated with the presence of proteinuria $(P=0.243)$ or diabetes mellitus $(P=0.772)$.

A considerable number of respondents (65.1\%) knew what hypertension meant and $55.6 \%$ knew at least two causes of hypertension. However, only $23.4 \%$ of respondents knew two or more complications of poor blood pressure control, and $64 \%$ were expecting a cure from treatment (Table 2).

A significant number of participants $(68.7 \%)$ reported low adherence to antihypertensive medication (Figure 1). The reasons cited for low adherence are shown in Table 3. The Morisky Medication Adherence Scale-8 (MMAS-8) used, showed a Cronbach's alpha of 0.78 implying high internal consistency. 
Table I Characteristics of study participants

\begin{tabular}{|c|c|c|}
\hline Parameter & $\begin{array}{l}\text { Frequency } \\
(n=252)\end{array}$ & Percent \\
\hline \multicolumn{3}{|l|}{ Mean age $\pm S D$ (years) $56.6 \pm 12.7$} \\
\hline \multicolumn{3}{|l|}{ Sex } \\
\hline Male & 143 & 56.7 \\
\hline Female & 109 & 43.3 \\
\hline \multicolumn{3}{|l|}{ Marital status } \\
\hline Single & 24 & 9.5 \\
\hline Married & 159 & 63.1 \\
\hline Divorced/separated/widowed & 69 & 27.4 \\
\hline \multicolumn{3}{|l|}{ Occupation } \\
\hline Trader/self-employed & 112 & 44.4 \\
\hline Farmer & 68 & 26.9 \\
\hline Civil servant & 35 & 13.9 \\
\hline Pensioner & 13 & 5.2 \\
\hline Student & 8 & 3.2 \\
\hline Clergy & 8 & 3.2 \\
\hline Unemployed & 8 & 3.2 \\
\hline \multicolumn{3}{|l|}{ Educational status } \\
\hline Primary & 72 & 28.6 \\
\hline Secondary & 105 & 41.6 \\
\hline Tertiary & 44 & 17.5 \\
\hline No formal education & 31 & 12.3 \\
\hline \multicolumn{3}{|l|}{ Blood pressure category (JNC-VII) } \\
\hline Normal & 15 & 6 \\
\hline Prehypertension & 68 & 27 \\
\hline Stage I & 99 & 39.3 \\
\hline Stage 2 & 70 & 27.8 \\
\hline \multirow{2}{*}{\multicolumn{3}{|c|}{$\begin{array}{l}\text { Mean duration of hypertension } \\
\text { diagnosis } \pm S D \text { (years) } 6.1 \pm 3.3\end{array}$}} \\
\hline & & \\
\hline \multicolumn{3}{|l|}{ Mean BMI $\pm S D\left(\mathrm{~kg} / \mathrm{m}^{2}\right) 27.3 \pm 3.5$} \\
\hline \multicolumn{3}{|l|}{ Mean systolic BP $\pm S D(m m H g) ~ 145 \pm 18$} \\
\hline Mean diastolic $\mathrm{BP} \pm \mathrm{SD}(\mathrm{mmHg}) 80 \pm 12$ & & \\
\hline
\end{tabular}

Abbreviations: SD, standard deviation; BP, blood pressure; BMI, body mass index; JNC-VII, Seventh Report of the Joint National Committee on Prevention, Detection and Evaluation of High Blood Pressure.

There was a disparity between the participants' knowledge of lifestyle modification in the management of hypertension and their practice of the relevant measures (Figure 2). Among those aware of salt restriction as a lifestyle modification, civil servants (adjusted odds ratio [OR] 0.12; 95\% confidence interval [CI] 0.02-0.96) and those with a longer duration since diagnosis of hypertension (adjusted OR 0.78; 95\%

Table 2 Participants' basic knowledge of hypertension, causes, complications and treatment outcomes

\begin{tabular}{lll}
\hline Parameter & Frequency & Percentage \\
\hline Meaning of hypertension & 164 & 65.1 \\
Causes of hypertension $(\geq 2)$ & 140 & 55.6 \\
$\begin{array}{l}\text { Consequences of poor blood } \\
\text { pressure control }(\geq 2)\end{array}$ & 59 & 23.4 \\
$\begin{array}{l}\text { Expectations of treatment } \\
\quad \text { Cure }\end{array}$ & \\
$\quad$ Control for life if cause is not known & 98 & 64.0 \\
\hline
\end{tabular}

CI 0.68-0.89) were less likely to practice salt restriction. Respondents who were currently married were more likely to practice salt restriction (adjusted OR 2.35; 95\% CI $1.10-5.00)$.

None of the sociodemographic variables assessed were found to be associated with the likelihood of practice of regular exercise among respondents who were aware of this lifestyle modification. Those with only secondary level of formal education were less likely to attempt weight reduction, despite being aware of its importance in blood pressure control (adjusted OR 0.13; 95\% CI 0.03-0.52).

\section{Discussion}

Although adequate blood pressure control $(<140 / 90 \mathrm{mmHg})$ is a major approach in reduction of the morbidity and mortality related to cardiovascular disease, achieving this target has remained a global challenge. Better control is needed, especially among Africans, because reports have shown that they have worse hypertension-related outcomes, including higher rates of fatal stroke, heart disease, and end-stage renal disease when compared with their white counterparts. ${ }^{46,47}$ However, rates of adequate blood pressure control vary widely globally and in Nigeria. The low rate of blood pressure control (32.9\%) obtained in this study is consistent with the $31 \%$ reported in Kano, Nigeria, ${ }^{38}$ the $31.4 \%$ reported in Abeokuta, Nigeria, ${ }^{48}$ and the $34 \%$ reported in the USA. ${ }^{19}$ Further, it is lower than the $36 \%$ reported from Ibadan, ${ }^{41}$ the $42.7 \%$ reported from Sokoto, Nigeria, ${ }^{37}$ the $53.3 \%$ reported from Ilorin, Nigeria, ${ }^{49}$ the $35 \%$ previously reported in Umuahia, Nigeria, ${ }^{42}$ and the $39 \%$ reported in Cuba. ${ }^{50}$ The majority of our study participants were traders, who tend to sit in one place to conduct their business (sedentary lifestyle) and may not undertake regular exercise. In addition, these traders spend most of their day at the market and depend on food vendors for most of their meals. Food from these sources is often salt-laden to improve taste. All these factors can adversely affect blood pressure control and contribute to low blood pressure control rates. However, the blood pressure control rate in this study was higher than the $12.4 \%$ reported in Zaria, Nigeria, ${ }^{40}$ the $24.2 \%$ from Port Harcourt, Nigeria, ${ }^{51}$ the $29.4 \%$ in Edo State, Nigeria, ${ }^{7}$ and the $10 \%$ reported in some parts of Europe. ${ }^{52}$ The mean duration since diagnosis of hypertension and hence the duration of drug treatment was higher in our study, and could account for the higher blood pressure control rate when some of these studies are compared. In general, these figures indicate that achieving optimal blood pressure control is still a challenge worldwide. 


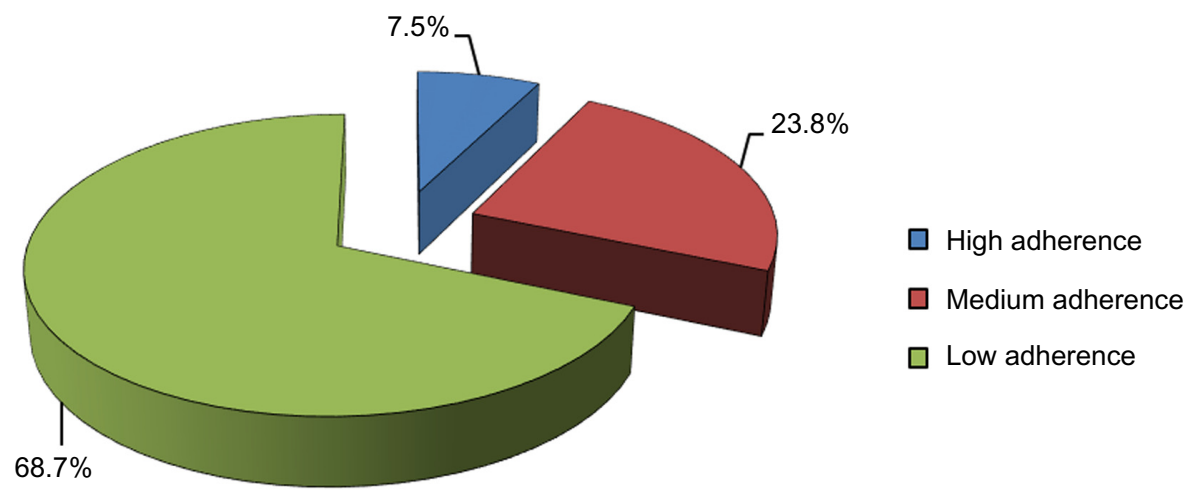

Figure I Adherence pattern of participants.

Hypertension may exist in association with other comorbidities in which there are compelling indications for use of specific medications. ${ }^{19}$ Some of these comorbidities including diabetes, chronic kidney disease, heart failure, and ischemic heart disease, can influence the outcome of blood pressure control. ${ }^{19}$ Proteinuria is an early indicator of kidney damage. ${ }^{53}$ In the setting of hypertension, it may be a marker of renal parenchymal disease as either a complication or cause of hypertension. It can also be an indicator of nephropathy in diabetics and pre-eclampsia in pregnant women. ${ }^{19}$ Unlike other studies ${ }^{54,55}$ this study did not reveal a significant association between presence of proteinuria or diabetes mellitus and blood pressure control. This may be due to the smaller sample size of our study compared to these other studies.

Patient education can improve blood pressure control. ${ }^{56}$ Before treatment is started, the hypertensive patient needs medical information on the meaning of hypertension, its causes, the duration of treatment, and the need for adherence to medication, lifestyle modification, and regular follow-up visits..$^{57} \mathrm{~A}$ well informed patient is more likely to accept treatment and comply with the physician's prescriptions, and be less likely to discontinue treatment prematurely. ${ }^{58}$ Misunderstanding of prescriptions on the part of patients (in terms of duration of use and dosing

Table 3 Reason for low level of adherence among participants

\begin{tabular}{lll}
\hline Reason & $\begin{array}{l}\text { Frequency } \\
(\mathbf{n = 1 7 3 )}\end{array}$ & Percentage \\
\hline Forgetfulness & 106 & 61.2 \\
Lack of funds & 98 & 56.6 \\
Feeling of well-being and cure & 34 & 19.6 \\
Advice from spiritualists & $\mathrm{I}$ & 0.6 \\
Herbal remedies & 3 & 1.73 \\
Side effects of medication & 30 & 17.3 \\
Measured blood pressure was low & 21 & 12.1 \\
High pill burden & 39 & 22.5 \\
\hline
\end{tabular}

of drugs) and failure to get drug refill was reported in a study by Okeahialam. ${ }^{59}$ Even though a good proportion of participants (more than 50\%) seemed to have a fair understanding of hypertension and its causes (Table 2), most did not understand the complications of poor blood pressure control. In addition, a sizeable number were ignorant of the duration and expectations of treatment for hypertension. These misconceptions and knowledge gaps have been reported to be particularly critical for Africans, who may have different perceptions of hypertension and different expectations of care ${ }^{60}$ Patients whose beliefs are discordant with traditional biomedical concepts of hypertension have poorer blood pressure control than those whose beliefs are concordant. ${ }^{60}$ Beliefs that hypertension is "curable" and not chronic, and that medication is needed only for hypertension-related symptoms may translate into poorer rates of medication adherence and blood pressure control.

Adherence is defined by the World Health Organization as the extent to which a person's behavior, ie, taking medication, following a diet, and/or implementing lifestyle changes, corresponds with the recommendations made by a health care provider. ${ }^{61}$ Adherence requires the patient's active participation in a therapeutic alliance established between the patient and physician. ${ }^{62}$ There are several methods available for measurement of adherence, ${ }^{62}$ none of which can be considered a gold standard. The use of standardized validated questionnaires and patient self-reporting is simple, inexpensive, and regarded as the most useful method in the clinical and outpatient settings. ${ }^{62}$ However, these measures are susceptible to error with increased time between visits and their results are easily distorted by patients. The low level of adherence to antihypertensive medication by the majority of participants in this study corroborates previous reports that adherence is poor in some patients with hypertension..$^{38,41,42,63}$ Factors identified in this study as being responsible for low adherence 


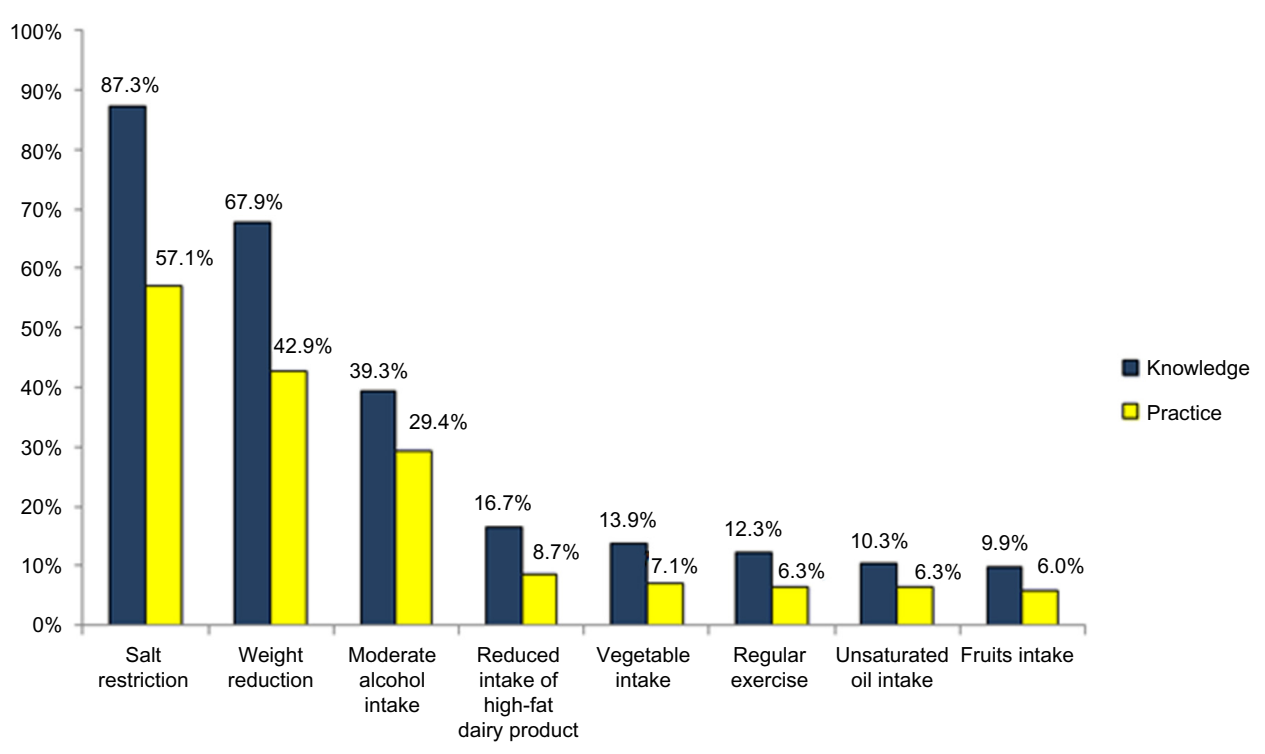

Figure 2 Knowledge and practice of lifestyle modification in management of hypertension among respondents.

are shown in Table 3. Suffice it to say that forgetting to take antihypertensive medication is not a problem that adult patients overcome. This has been attributed to competing psychosocial demands in everyday life, ${ }^{42,64}$ especially among traders. Physicians' awareness of this is crucial for optimal care of adult hypertensive patients in Nigeria.

A financial impediment to drug purchase was noted in $56.6 \%$ of participants. This raises the issue of the role of the patient's socioeconomic status in blood pressure control, as discussed in other studies..$^{17,40,42}$ Nigeria's health expenditure is ranked among the lowest in the world, ${ }^{65}$ and about $70 \%$ of Nigerians live below the poverty line. ${ }^{66}$ Newer and more potent antihypertensive drugs are available, but are largely unaffordable for the majority of patients. The nature of essential hypertension as a lifelong disease, the need for daily medication, and the cost and side effects of drugs all need to be taken into consideration in the design of an effective therapeutic regimen for hypertensive individuals.

The effectiveness of self-monitoring of blood pressure in improving blood pressure control is also well documented. .7,68 $^{6}$ Mengden et al found average blood pressure reductions of 19.3/11.9 mmHg at 6 months in a home monitoring group versus 10.6/8.8 mmHg in a usual care group. ${ }^{69}$ Some participants in our study showed evidence of home blood pressure monitoring that was quite commendable. However, $12.1 \%$ discontinued their medications when they found that their blood pressure was lower than earlier measurements. This habit is incompatible with good practice and should be discouraged.
The JNC-VII ${ }^{19}$ and the Nigerian Hypertension Society guideline for the management of hypertension ${ }^{70}$ recommend lifestyle modification for all patients with hypertension or prehypertension. These modifications, previously referred to as nonpharmacologic therapy, serve as adjunctive therapy for hypertension and include weight reduction, increased physical activity, moderation of dietary sodium and alcohol intake, and following the Dietary Approach to Stop Hypertension eating plan. The effectiveness of these lifestyle measures in preventing and treating hypertension is well established..$^{71,72}$ Knowledge about lifestyle modification in our study was generally poor, and the knowledge-practice discordance noted is particularly alarming. This result is consistent with other similar reports of poor knowledge and application of lifestyle measures for blood pressure control among patients with hypertension. ${ }^{40,41,73}$

\section{Conclusion}

Poor blood pressure control in the majority of participants was an important finding in this study. Although this could be largely multifactorial, identified patientrelated barriers include inadequate knowledge of the consequences of poor blood pressure control, unrealistic expectations of treatment, poor adherence to medications (forgetfulness and financial constraints being mainly responsible for this), poor knowledge of lifestyle measures, and a knowledge-practice gap in application of lifestyle measures. 


\section{Recommendations}

Achieving control of hypertension requires a team effort. Although both physician and patient factors need to be addressed to improve hypertension control, emphasis should be placed on interdisciplinary team-based care utilizing health care providers such as nurses, physician assistants, and pharmacists. Team-based care has been shown to have the greatest impact of all the strategies available for improving blood pressure control. ${ }^{74}$

In addition, patient education, addressing misconceptions about hypertension, regular home blood pressure monitoring, the need for consistency in drug and nondrug measures prescribed as well as regular follow-up need to be addressed at each clinic visit. Physicians should prescribe drugs which are pocket-friendly and have a low side effect profile. Up to $17.3 \%$ of our participants who were not adherent to drugs attributed this to the side effects of medications. Premature discontinuation of treatment due to drug side effects and lack of money to buy drugs interrupt consistent use of antihypertensive medication. ${ }^{40,75}$

Physician and health system barriers also contribute to poor blood pressure control, but these were not the focus of this study. However, they also need to be identified and corrected for any meaningful control of blood pressure to be achieved. They also represent an area for further research as few relevant data exist in the literature. These measures, if taken into consideration, will help to stem the rising tide of the hypertension pandemic and its complications in our region.

\section{Limitations}

Blood pressure control should ideally be assessed using the average of two or more consecutive blood pressure readings taken on different occasions. However, this study was carried out as part of a screening exercise in which we did not have the benefit of knowing participants' previous blood pressure readings and there was no subsequent follow-up of the participants. Medication adherence was assessed using the Morisky's questionnaire which has not been validated for use in this population. ${ }^{44}$ Further studies are needed in our population to validate the use of this tool. The assessment of the practice of lifestyle modification among participants in this study was limited by the use of subjective responses alone. This was due to a paucity of validated tools to objectively assess this vital aspect of patient management.

\section{Disclosure}

The authors report no conflicts of interest in this work.

\section{References}

1. Kearney PM, Whelton M, Reynolds K, Muntner P, Whelton PK, He J. Global burden of hypertension: analysis of worldwide data. Lancet. 2005;365(9455):217-223.

2. Kearney PM, Whelton M, Reynolds K, Whelton PK, He J. Worldwide prevalence of hypertension: a systematic review. J Hypertens. 2004; 22(1):11-19.

3. Macgregor GA. Africa and salt - the need for action now. Paper presented at The Second Pan-African Meeting on Hypertension, International Forum for Hypertension Control and Prevention in Africa, May 12-13, 2007, Nairobi, Kenya.

4. Briganti EM, Shaw JE, Chadban SJ, et al. Untreated hypertension among Australian adults: the 1999-2000 Australian Diabetes, Obesity and Lifestyle Study (AusDiab). Med J Aust. 2003;179(3):135-139.

5. International Conference for Cardiovascular Disease Control and Prevention in Africa. WHL Newsletter. 2003;88:3. Available at http:// www.worldhypertensionleague.org/Documents/newsletters/2003/ wh188.pdf. Accessed February 24, 2014.

6. Akinkugbe OO. Noncommunicable Disease in Nigeria: Final Report of a National Survey. Lagos, Nigeria: Federal Ministry of Health and Social Services; 1997

7. Ogunlesi A, Osotimehin B, Abbiyessuku F, et al. Blood pressure and educational level among factory workers in Ibadan, Nigeria. J Hum Hypertens. 1991;5(5):375-380.

8. Arogundade F, Sanusi A, Hassan M, Gbadegesin A, Olarinoye F, Otuyemi B. Undiagnosed hypertension and proteinuria in a market population in Ile Ife, Nigeria. Arab J Nephrol Transplant. 2011;4(3): 141-146.

9. Oladapo OO, Salako L, Sadiq O, Shoyinka K, Adedapo K, Falase AO. A prevalence of cardiometabolic risk factors among a rural Yoruba South-Western Nigerian population; a population-based survey. Cardiovasc J Afr. 2010;21(1):26-31.

10. Ulasi II, Ijoma CK, Onodugo OD. Community based study of hypertension and cardiometabolic syndrome in semi-urban and rural communities in Nigeria. BMC Health Serv Res. 2010;10(71).

11. Ogah OS, Madukwe OO, Onyeonoro UU, et al. Cardiovascular risk factors and non-communicable diseases in Abia state, Nigeria: report of a community-based survey. Int J Med Biomed Res. 2013;2(1): 57-68.

12. Onwubere BJ, Ejim EC, Okafor CI, et al. Pattern of blood pressure indices among the residents of a rural community in South East Nigeria. Int $J$ Hypertens. 2011;2011:621074.

13. [No authors listed]. The Sixth Report of the Joint National Committee on Prevention, Detection, Evaluation and Treatment of High Blood Pressure (JNC VI). Arch Intern Med. 1997;157(21):2413-2446.

14. Berlowitz DR, Ash AS, Hickey EC, et al. Inadequate management of blood pressure in a hypertensive population. $N$ Engl $\mathrm{J} \mathrm{Med}$. 1998;339(27):1957-1963.

15. Wang L, Wei T. Blood pressure control in patients with hypertension: a community-based study. Clin Exp Hypertens. 2006;28(1):41-46.

16. White F, Wang L, Jelinek H. Awareness and pharmacotherapy of hypertension in a rural community. Med Princ Pract. 2009;18(4): 261-265.

17. Omuemu VO, Okogie OH, Omuemu CE. Awareness of high blood pressure status, treatment and Control in a rural community in Edo State. Niger J Clinical Pract. 2007;10(3):208-212.

18. Whitworth JA. 2003 World Health Organization (WHO)/International Society of Hypertension (ISH) statement on management of hypertension. J Hypertens. 2003;21(11):1983-1992.

19. Chobanian AV, Bakris GL, Black HR, et al. Seventh Report of the Joint National Committee on Prevention, Detection, Evaluation, and Treatment of High Blood Pressure. Hypertension. 2003;42(6): 1206-1252.

20. Chalmers J, MacMahon S, Mancia G, et al. 1999 World Health Organization-International Society of Hypertension Guidelines for the management of hypertension. Guidelines sub-committee of the World Health Organization. Clin Exp Hypertens. 1999;21(5-6):1009-1060. 
21. Odedosu T, Schoenthaler A, Vieira DL, Agyemang C, Ogedegbe G. Overcoming barriers to hypertension control in African Americans. Cleve Clin J Med. 2012;79(1):46-56.

22. Douglas JG, Ferdinand KC, Bakris GL, Sowers JR. Barriers to blood pressure control in African Americans. Overcoming obstacles is challenging, but target goals can be attained. Postgrad Med. 2002;112(4):51-52.

23. Knight EL, Bohn RL, Wang PS, Glynn RJ, Mogun H, Avorn J. Predictors of uncontrolled hypertension in ambulatory patients. Hypertension. 2001;38(4):809-814.

24. Chobanian AV. Control of hypertension - an important national priority. N Engl J Med. 2001;345(7):534-535.

25. Miller NH, Hill M, Kottke T, Ockene IS. The multilevel compliance challenge: recommendations for a call to action. A statement for healthcare professionals. Circulation. 1997;95(4):1085-1090.

26. Blumhagen D. Hypertension: a folk illness with a medical name. Cult Med Psychiatry. 1980;4(3):197-224.

27. Meyer D, Leventhal H, Gutmann M. Common-sense models of illness: the example of hypertension. Health Psychol. 1985;4(2):115-135.

28. Ogedegbe G, Mancuso CA, Allegrante JP. Expectations of blood pressure management in hypertensive African-American patients: a qualitative study. $J$ Natl Med Assoc. 2004;96(4):442-449.

29. Lang T. Social and economic factors as obstacles to blood pressure control. Am J Hypertens. 1998;11(7):900-902.

30. Mehta SS, Wilcox CS, Schulman KA. Treatment of hypertension in patients with comorbidities: results from the study of hypertensive prescribing practices (SHyPP). Am J Hypertens. 1999;12(4 Pt 1): 333-340.

31. Wang L. Physician-related barriers to hypertension management. Med Princ Pract. 2004;13(5):282-285.

32. Hicks LS, Shaykevich S, Bates DW, Ayanian JZ. Determinants of racial/ ethnic differences in blood pressure management among hypertensive patients. BMC Cardiovasc Disord. 2005;5(1):16.

33. Hajjar I, Miller K, Hirth V. Age-related bias in the management of hypertension: a national survey of physicians' opinions on hypertension in elderly adults. J Gerontol A Biol Sci Med Sci. 2002;57(8): 487-491.

34. Shea S, Misra D, Ehrlich MH, Field L, Francis CK. Correlates of nonadherence to hypertension treatment in an inner-city minority population. Am J Public Health. 1992;82(12):1607-1612.

35. Bone LR, Hill MN, Stallings R, et al. Community health survey in an urban African-American neighborhood: distribution and correlates of elevated blood pressure. Ethn Dis. 2000;10(1):87-95.

36. Wee LE, Koh GC. Individual and neighborhood social factors of hypertension management in a low-socioeconomic status population: a community-based case-control study in Singapore. Hypertens Res. 2012;35(3):295-303.

37. Isezuo AS, Njoku CH. Blood pressure control among hypertensives managed in a specialised health care setting in Nigeria. Afr J Med Med Sci. 2003;32(1):65-70.

38. Sani MU, Mijinyawa MS, Adamu B, Abdu A, Borodo MM. Blood pressure control among treated hypertensives in a tertiary health institution. Niger J Med. 2008;17(3):270-274.

39. Obinna IE, Patrick OU, Izuchukwu LN. Prevalence, awareness, treatment and control of hypertension in a Nigerian population. Health Psychol. 2010;2:731-735.

40. Oyati AI, Orogade AA, Danbauchi SS, Azuh PC. Awareness, treatment and control of hypertension among hypertensives in Zaria. Journal of Medicine in the Tropics. 2011;13(2):139-144.

41. Salako BL, Ajose FA, Lawani E. Blood pressure control in a population where antihypertensives are given free. East Afr Med J. 2003;80(10): 529-531.

42. Iloh GUP, Ofoedu JN, Njoku PU, Amadi AN, Godswill-Uko EU. Medication adherence and blood pressure control amongst adults with primary hypertension attending a tertiary hospital primary care clinic in Eastern Nigeria. Afr J Prim Health Care Fam Med. 2013;5(1): 446-452.
43. Araoye MO. Research Methodology with Statistics for Health and Social Sciences. Ilorin West, Nigeria: Nathadex Publishers; 2004.

44. Morisky DE, Ang A, Krousel-Wood M, Ward HJ. Predictive validity of a medication adherence measure in an outpatient setting. $J$ Clin Hypertens (Greenwich). 2008;10(5):348-354.

45. [No authors listed]. Classification and diagnosis of diabetes mellitus and other categories of glucose intolerance. National Diabetes Data Group. Diabetes. 1979;28(12):1039-1057.

46. Giles WH, Kittner SJ, Hebel JR, Losonczy KG, Sherwin RW. Determinants of black-white differences in the risk of cerebral infarction. The National Health and Nutrition Examination Survey Epidemiologic Follow-up Study. Arch Intern Med. 1995;155(12):1319-1324.

47. Klag MJ, Whelton PK, Randall BL, Neaton JD, Brancati FL, Stamler J. End-stage renal disease in African-American and white men. 16-year MRFIT findings. JAMA. 1997;277(16):1293-1298.

48. Ayodele OE, Alebiosu CO, Salako BL. Differential control of systolic and diastolic blood pressure in blacks with essential hypertension. J Natl Med Assoc. 2004;96(3):310-314.

49. Olanrewaju TO, Aderibigbe A, Chijioke A, et al. Descriptive analysis of blood pressure control among treated hypertensive patients in a tertiary hospital in Nigeria. Afr J Med Med Sci. 2011;40(3): 207-212.

50. Cooper RS, Ordunez P, Ferrer MDI, Munoz JCB, Espinosa-Brito A. Cardiovascular disease and associated risk factors in Cuba: prospects for prevention and control. Am J Public Health. 2006;96(1):94-101.

51. Akpa MR, Alasia DD, Emem-Chioma PC. An appraisal of hospital based blood pressure control in Port Harcourt Nigeria. Nigerian Health Journal. 2008;8(1-2):27-30.

52. Wolf-Maier K, Cooper RS, Kramer H, et al. Hypertension treatment and control in five European countries, Canada, and the United States. Hypertension. 2004;43(1):10-17.

53. National Kidney Foundation. KDIGO 2012 clinical practice guideline for the evaluation and management of chronic kidney disease. Kidney Int Suppl. 2013;3(1):19.

54. Davis TE, Millns H, Stratton IM, Holman RR, Turner RC, Group UKPDS. Risk factors for stroke in type 2 diabetes mellitus: United Kingdom Prospective Diabetes Study (UKPDS) 29. Arch Intern Med. 1999;159(10):1097-1103

55. Fagan TC, Sowers J. Type 2 diabetes mellitus: greater cardiovascular risks and greater benefits of therapy. Arch Intern Med. 1999;159(10): 1033-1034.

56. Green LW, Levine DM, Wolle J, Deeds S. Development of randomized patient education experiments with urban poor hypertensives. Patient Couns Health Educ. 1979;1(3):106-111.

57. Levine DM, Green LW, Deeds SG, Chwalow J, Russell RP, Finlay J. Health education for hypertensive patients. JAMA. 1979; 241(16):1700-1703.

58. Iso H, Shimamoto T, Yokota K, Sankai T, Jacobs DR Jr, Komachi Y. Community-based education classes for hypertension control. A 1.5-year randomized controlled trial. Hypertension. 1996;27(4):968-974.

59. Okeahialam BN. Adherence and preference issues in anti-hypertensive therapy: experience from a private medical facility in Jos, Nigeria. Journal of Medicine in the Tropics. 2011;13:11-14.

60. Heurtin-Roberts S, Reisin E. The relation of culturally influenced lay models of hypertension to compliance with treatment. Am J Hypertens. 1992;5(11):787-792.

61. World Health Organisation. Essential Medicines and Health Products Information Portal. Adherence to long-term therapy - evidence for action. 2003. Available from: http://apps.who.int/medicinedocs/en/d/ Js4883e/6.1.1.html. Accessed February 21, 2014.

62. Osterberg L, Blaschke T. Adherence to medication. $N$ Engl J Med. 2005;353(5):487-497.

63. Bramley TJ, Gerbino PP, Nightengale BS, Frech-Tamas F. Relationship of blood pressure control to adherence with antihypertensive monotherapy in 13 managed care organizations. J Manag Care Pharm. 2006; 12(3):239-245. 
64. Wang PS, Bohn RL, Knight E. Non-compliance with antihypertensive medications, the impact of depressive symptoms and psychosocial factors. J Gen Intern Med. 2002;17(7):504-511.

65. World Health Organisation. World health report on reducing risks, promoting healthy life. Geneva, Switzerland: World Health Organisation; 2002. Available from: http://www.who.int/whr/2002/ en/. Accessed May 22, 2014.

66. Central Intelligence Agency. The World Factbook - Nigeria. May 2005. Available from: https://www.cia.gov/library/publications/the-worldfactbook/geos/ni.html. Accessed February 24, 2014.

67. Yarows SA, Julius S, Pickering TG. Home blood pressure monitoring. Arch Intern Med. 2000;160(9):1251-1257.

68. Johnson AL, Taylor DW, Sackett DL, Dunnett CW, Shimizu AG. Selfrecording of blood pressure in the management of hypertension. Can Med Assoc J. 1978;119(9):1034-1039.

69. Mengden T, Uen S, Baulmann J, Vetter H. Significance of blood pressure self-measurement as compared with office blood pressure measurement and ambulatory 24-hour blood pressure measurement in pharmacological studies. Blood Press Monit. 2003;8(4):169-172.
70. [No authors listed]. Guidelines for the management of hypertension in Nigeria. May 1996. Available from: http://www.nigerianheart.org/ downloads/management_of_hypertension.pdf. Accessed November 24 2013.

71. Moore TJ, Conlin PR, Ard J, Svetkey LP. DASH (Dietary Approaches to Stop Hypertension) diet is effective treatment for stage 1 isolated systolic hypertension. Hypertension. 2001;38(2):155-158.

72. Appel LJ, Champagne CM, Harsha DW, et al. Effects of comprehensive lifestyle modification on blood pressure control: main results of the PREMIER clinical trial. JAMA. 2003;289(16):2083-2093.

73. Ike SO, Aniebue PN, Aniebue UU. Knowledge, perceptions and practices of lifestyle-modification measures among adult hypertensives in Nigeria. Trans R Soc Trop Med Hyg. 2010;104(1):55-60.

74. Walsh JM, McDonald KM, Shojania KG, et al. Quality improvement strategies for hypertension management: a systematic review. Med Care. 2006;44(7):646-657.

75. Akpa MR, Agomuoh DR, Odia OJ. Drug compliance among hypertensive patients in Port Harcourt, Nigeria. Niger J Med. 2005;(14):55-57.
International Journal of General Medicine

\section{Publish your work in this journal}

The International Journal of General Medicine is an international, peer-reviewed open-access journal that focuses on general and internal medicine, pathogenesis, epidemiology, diagnosis, monitoring and treatment protocols. The journal is characterized by the rapid reporting of reviews, original research and clinical studies across all disease areas.

\section{Dovepress}

A key focus is the elucidation of disease processes and management protocols resulting in improved outcomes for the patient.The manuscript management system is completely online and includes a very quick and fair peer-review system. Visit http://www.dovepress.com/ testimonials.php to read real quotes from published authors.

Submit your manuscript here: http://www.dovepress.com/international-journal-of-general-medicine-journal 